\title{
Exploration and Practice of Robot Innovative and Practical Teaching Reform in University
}

\author{
Zhu Qixin \\ The Suzhou University of Science and Technology \\ Suzhou, China
}

\author{
Wang Bangfu \\ The Suzhou University of Science and Technology \\ Suzhou, China
}

\author{
Wang Siming \\ Lanzhou Jiaotong University \\ Lanzho, China
}

\begin{abstract}
The robot innovative engineering practice teaching is aimed at cultivating students' innovative consciousness and engineering practice ability. This paper expounds the present situation of robot practice teaching and its existing problems, training objectives and teaching reform. It aims to explore the reform of teaching system and mode of robot innovative engineering practice, offering advice and suggestions for the improvement of students' innovation awareness and engineering practice ability in robot practice teaching.
\end{abstract}

Keywords-Innovation and Practice Teaching, Robot, Teaching Reform

\section{The Status of Traditional Robot Practice EDUCATION AND ITS EXISTING PROBLEMS [1-3]}

Robot is the excellent product of highly developed human science and technology. It combines human wisdom and machinery, and is one of the highest achievements of mankind in transformation of the nature. In recent years, especially with the bringing forward of industry 4.0, the robot science and industry has become a hotly contested spot in national science and technology development strategies and economic industry. At present, the robot has entered our daily life and industrial production, and become an important part of human society. The expansion and popularity of the robot industry has put forward higher requirements for colleges and universities as talent training base on robot education. However, the problems that our university has in robot education can't be ignored:

\section{A. Teaching Content Can't Keep up with the Development Speed of Robot}

With the introduction and application of industry 4.0, countries have invested a lot of energy and material resources in the R\&D and manufacture of robots. The robot industry has developed very rapidly. But our syllabus has not changed much in the past few years. It lags far behind the development of robot technology. At the same time, teachers teach basically according to the syllabus, and haven't updated the content of teaching much. Most of the curriculum is about traditional basic content. Some of them may be no longer useful, and can't teach students the advanced development and latest results of the subject of robot.

\section{B. Unreasonable Setting on Teaching Links}

There are unreasonable places in robot teaching. Most of the colleges and universities mainly focus on theory in robot teaching, and lack practice teaching. The teachers put too much emphasis on theory course, lacking practice teaching link. The practical link is the best way to cultivate students' engineering practice ability and innovation consciousness. It is also an important link to train students' ability to use learned knowledge to analyze and solve practical problems.

\section{Education Robot Products Lack Specification}

At present, there are many manufacturers producing and selling education robot products in the market. And most of them are small businesses, and have no uniform standards and norms. So they all have their own systems which are incompatible to each other. Their system openness is low, basically impossible to carry out secondary development, which is not very useful for students' learning.

\section{Students' Interest Is Not High}

Robot education teaching is mainly about boring theoretical knowledge, lacking practical hands-on teaching links, and can't effectively mobilize students' interest of learning robots.

\section{Cultivating OBJECTIVES OF RoBOt INNOVATION AND PRACTICE PlatFoRM[4-6]}

In general, robot innovative engineering practice can develop students' abilities in the following aspects:

\section{A. Master Basic Knowledge and Flexible Application Ability}

Through robot innovation engineering practice, students can deepen their understanding of knowledge, such as mechanical design and manufacturing technology, circuit technology, electronic technology, single chip technology, automatic control theory and technology, and master basic practical circuit design, flexibly applying learned theoretical knowledge to robot innovation engineering practice. 


\section{B. Comprehensive Application of Professional Knowledge}

Robot is a typical mechatronics product. Mechatronics product is an organic combination of mechanical technology and electronic technology. Therefore, in the process of robot innovation engineering practice, students need to build corresponding robot mechanical system and control system according to robot design functional requirements. Students need to learn to combine their learned subject knowledge of mechanical principles, mechanical design, mechanical manufacturing technology, circuit, digital electronics, analogical electronics, sensor technology, automatic control theory, SCM, computer control technology, mechanical and electrical integration technology, so as to develop students' ability to comprehensively apply multiple professional knowledge.

\section{Cultivate Students' Teamwork Spirit}

Robotics is a new and interdisciplinary, highly integrated subject. So it has very strong comprehensiveness, involving a lot of disciplines, such as circuit technology, digital and analogical electric technology, single chip technology, sensor technology, automatic control principle technology, mechanical manufacture and design, and mechanical and electrical integration technology. In the process of robot practice teaching and design, due to the limitations of students' knowledge level and practical ability, it is necessary for several students to form a learning group to play a team spirit and cooperate with each other in order to design and manufacture high quality robots. Team members should work in cooperation with a due division of labor, forming a good team. This is the cooperation mode that the future society needs. Therefore, robot practice teaching can cultivate the team spirit of students.

\section{Ability to Think Independently, Analyze and Solve Problems}

Robot innovation engineering practice process requires students team or team to independently complete the process from car body mechanical structure design, controller design, sensor application and testing information analysis and processing, power management, control software design and preparation, system installation and commissioning to the final construction of a complete mechatronics system. In the whole process, the robot learning group needs to access the relevant information, and independently completes sensor selection and placement, programming and debugging, and program demonstration. They need to find the solution to problems through group discussions and analysis. This process is a continuous improvement process, but also a process for students to grow.

\section{The CONSTRUCTION OF ROBOt INNOVATIVE PRACTICE} PLATFORM

\section{A. Practice Platform Hardware Construction}

To cultivate students' practical ability and innovation consciousness, we must have a good platform for engineering practice. Our university has built a training platform for students' practical innovation ability in the engineering training center: Robot Innovation Base. It is a practical base for cultivating students' engineering practice ability and innovation consciousness. The base conducts open laboratory management. It is a platform which provides students and teachers with innovation activities and research activities of different levels and specialties. The platform is divided into three parts:

(1) Mechanical design and manufacture platform using mechanical structure innovation as the main body. The platform mainly provides engineering practice teaching conditions for mechanical students, so that students are able to participate in simple robot innovation practice activities in the early grades, cultivating students' engineering practice ability, mechanical design and manufacturing capability and innovation consciousness.

(2) Electronic design production platform using electronic innovative design as the main body. It mainly provides students majoring in electronics, control and mechatronics with engineering practice teaching conditions. The platform is based on the electronic design and production practice of low-grade students, and improves students' electronic design production practice ability through design and manufacture of a variety of simple control circuits and systems. At the same time, with the of depth development of practice and improvement of students' ability, practical content can be deepened to let students carry out a higher level of design and production.

(3) Robot design platform based on the design and production of electromechanical system. It is a platform of comprehensive application based on the previous two platforms. The platform is a team collaboration platform. Students who want to enter the platform must complete the practical learning on one of the above two platforms first and have a certain basis. On the platform, they can form design teams based on the functional and design requirements of robots, and complete the design and production of robots together.

\section{B. Practice Platform "Software" Construction}

Due to the influence of traditional teaching idea and teaching mode, most of the colleges and universities emphasize the importance of theoretical teaching and neglect the importance of practical teaching, not to mention the construction of practical instructors. We also need to strengthen the construction of "software" while strengthening the construction of the hardware platform of robot innovative and practical teaching. Our school has treated the construction and development of practice instructor team seriously, and built up a high-quality practice teaching team with high practical skills, strong teaching ability and innovative consciousness. They are in line with practical teaching requirements and the scientific development of the school. In the construction of robot innovation and practice platform instructor team, we fully consider that robotics has integrated multi-subject knowledge. Therefore robot innovation and practice platform instructor team need a relatively stable and multi-disciplinary teacher team, so as to better guide and cultivate students' practical ability, innovative consciousness and competitive ability. While paying attention to the construction of the instructor team, we also pay attention to the construction of students team and echelon. Set up corresponding students team and echelon 
for students of different grades and subjects, and conduct school-level competition of which the degree of difficulty is slightly reduced to increase students' participation and enthusiasm in the robot competition, and on the other hand provide reference for school on selection of outstanding students team to participate in national and provincial competitions.

\section{REFORM AND EXPLORATION OF ROBOT INNOVATION ENGINEERING PRACTICE TEACHING}

\section{A. Highlight the Teaching Mode with Competition as Its Carrier}

The key of the innovation practice teaching mode is to find a feasible carrier, and the robot innovation engineering practice teaching takes the robot competition as the carrier. Through the robot competition, strengthen the quality of practical teaching; stimulate students' innovation awareness and initiative to learn. During the preparation of competition, students take the initiative to learn the relevant knowledge, conduct positive thinking, actively participate in training and form good learning habits of self-learning. It significantly improves the learning and teaching effect, not only enhancing engineering ability, but also consolidating and sublimating the professional knowledge in the training. Meanwhile, competition also helps students develop team spirit, safety awareness, environmental awareness and cost-saving awareness, further enhancing the students' operating skills and comprehensive quality.

\section{B. Focus on Innovative Education and Extend Prize-Winning Works to Classroom Teaching}

After a period of robot innovation engineering practice education, a large number of high level student competition winning works are produced. These works are very convincing for the junior students, and can stimulate students' selfconfidence, initiative and interest in learning. Practical teaching can use these works as content and object. Teachers explain the principles and problem-solving ideas and methods of these works to students, as well as the basic theoretical knowledge comprehensively used in these works, and students discuss and put forward personal views or suggestions about specific works Students who have mature ideas and ability can re-design the works.

\section{Conduct School-Enterprise Cooperation to Complement Each Other and Increase Classroom Teaching Project Case}

With the development of industrial technology 4.0, the robot technology has been widely used in the surrounding manufacturing enterprises. Introduce some of the typical robot technology cases into the curriculum teaching, and arrange engineers to explain it to students, including project background, design requirements, technical routes, detailed programs, commissioning process, acceptance criteria and the entire project management approach. Through the explanation of the project case, the students have a comprehensive understanding of the management and implementation of the actual project, which is very helpful to increase their engineering consciousness and engineering practice ability. At the same time, strengthen the school-enterprise cooperation, select and employ right number of technical staff with rich practical experience from the enterprise as part-time practice teaching instructors, who regularly or irregularly come to school to teach students and open professional lectures, teaching students the latest technology from the forefront of actual production. On the other hand, introduce and use enterprise practice base. Let enterprise provide externalcampus practice base for school. Strengthen the building of colaboratory, and let the technical backbone of enterprise act as practice instructor. Expand and update the content and requirements of practice, improve the authenticity and engineering of practice teaching, let students feel the "real" engineering practice training, so as to form and build an excellent engineering practice environment.

\section{Attach Importance to Team Building}

Suzhou University of Science and Technology has been committed to the construction of robot innovative education team for many years, and achieved certain results. Relying on school's provincial experimental teaching and practical education center-Mechanical Engineering Integrated Training Center, four robot team directions and one robot research institute have been formed, as shown in Figure 1. Four robot team directions are mainly made up of students and guided by the teacher. Their aim is to cultivate students' innovative practice ability, and participate in all kinds of college students subject competitions; digital intelligence research institute is mainly a scientific research base for teachers team, and is responsible for management of the four team directions set under it.

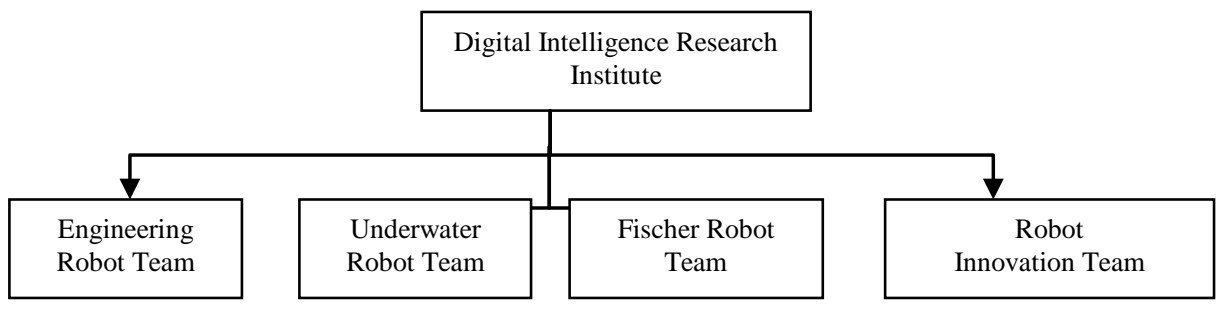

Fig. 1. Robot team 
In addition to laboratories for general basic training, the school also has special robot training laboratories, such as Robot Innovation Laboratory, Fischer Robot Laboratory. The school has opened robot elective courses and robot science lectures to stimulate students' interest. Meanwhile, it also opens courses such as robot introduction in relevant specialties for the further study of students. For students who have obtained good rankings in various subject competitions, the school not only gives priority to them in the evaluation, but also gives them extracurricular credits to motivate students' initiative. For teachers who guide students to obtain rankings in the competition, school will recognize the result and give priority to them in the year-end assessment and professional title evaluation, thus improving teachers' enthusiasm.

\section{RESULTS AND SUMMARY}

The cultivation of students' innovative ability is the key to the cultivation of high-level talents in today's society, and the direction of teaching reform in colleges and universities. As an intelligent automatic device combining machine, electricity, light, liquid, control into one, the robot is an effective platform to train the practical innovation ability of engineering students. In recent years, our students have won 7 national and provincial second and third prizes and 82 rewards certificates in China Robot Contest RoboCup (China region) and other robot contests. This shows that our school has achieved good teaching results in the reform of robot innovative engineering practice teaching. At the same time, it also promotes the upgrading of teachers' academic standards and updates their concept of teaching reform.

\section{REFERENCES}

[1] Bi Jintao. Exploration of Robot Teaching New Reform Ideas in Colleges and Universities [J]. Information and Communication, 2013, 3: 266-267.

[2] Zhan Qiang. Exploration and Practice of Robot Teaching Reform [J]. Modern Educational Technology, 2010, 20 (3): 144-146: 139.

[3] Zhang Jianping. Robot Education: Status Quo, Problems and Promotion Strategies [J] China Electrification Education, 2006, 20: 65-68.

[4] Dong Cuimin.Use Robot Education as Platform to Cultivate College Students' Innovative Consciousness and Ability [J]. Laboratory Research and Exploration, 2011, 9 (30): 223-224: 320.

[5] Liu Shujun. Engineering Practice Model Based on Robot Innovation Training [J]. Curriculum Education Research, 2012, 10 (second): 241242.

[6] Li Xia. "Robot Technology Base_Course Teaching Exploration" Interest-driven Learning Method Exploration [J]. Agricultural Network Information, 2015,1: 132-135. 